\title{
AN APPROACH FOR EFFECTIVE VALUATION OF NUMEROUS REAL ESTATE OBJECTS
}

\author{
Mirosław Dytczak \\ Opole University of Technology \\ Opole, Poland \\ E-mail: mdytczak@gmail.com \\ Beata Gotowała \\ Agency for Military Property, Warsaw \\ Szczecin, Poland \\ E-mail: beatagotowala@op.pl
}

\begin{abstract}
Value of real estate objects depends on numerous factors. Many of them are tangible. There are, however, intangible factors which can influence value of the objects a lot. Application of a thorough multi-attribute evaluation approach is therefore required for a trustful valuation of the objects. Additional problems with objects evaluation result from multiplicity of real estate objects. An approach is proposed in the paper to deal with multi-attribute evaluation of real estate objects which includes influence of intangibles. The approach consists of two main phases. The first phase is devoted to identification of representatives of subpopulations of evaluated objects. The second phase deals with direct pair-wise comparisons of representative objects using AHP/ANP. The approach is aimed at application for valuation of real estate objects in a Polish governmental institution which governs public real estate objects.
\end{abstract}

Keywords: real estate, valuation, massive, multi-attribute, AHP/ANP.

\section{Introduction}

A level of value of real estate objects results from different factors. They pertain to both features of objects themselves as well as to their location. Compulsory ways of valuation of real estate objects are defined in specialised regulations. The regulations oblige professional valuators to include all the factors which would affect value of objects.

Several object and location features are of an intangible nature. Their presence makes value of the object susceptible to very subjective judgments and a kind of manipulation. Attaining at fair value of objects requires therefore application of appropriate approaches for dealing with intangible factors. Their application would dramatically improve quality of valuation outcomes. It is especially true in the case of valuation of multiple objects where valuation consistency is of paramount interest of organizations managing large sets of objects i.e. real estate governmental management agencies. Application of a transparent valuation scheme would not only define fair values of objects. It would also deliver means for verif ication of valuation analysis outcomes delivered by professional valuators.

An approach suitable for valuation of numerous real estate objects is presented in the paper. It applies a two-phase analysis to deliver final values of real estate objects.

\footnotetext{
${ }^{*}$ Corresponding author
} 


\section{Real estate valuation process}

There are real estate management agencies which deal with operation of considerable number of objects. Outcomes of their activities depend on information about estimated features of managed objects. Adequate information about objects is therefore required to assure proper decision making. Value comprises one of the most important real estate attributes. Adequate estimation of real estate object value is therefore fundamental issue for decision making in a real estate management agency.

Real estate valuation takes the form of an official report delivered by a valuator. It is called a valuation statement. It includes description of considered real estate including features, their evaluation, other assumptions to valuation and calculations of final value. The available procedures for real estate valuation are included in official regulations. A valuator is obliged to apply procedure which is appropriate to purpose and other important features of a considered real estate object. It requires a valuator to provide a trustful value estimation based on all important object features. He or she is allowed, however, to subjective evaluations of intangible object attributes. In some cases, the regulations also permit a valuator to choose a valuation procedure alternative which he likes best.

Value of real estate objects results from numerous factors. They pertain to different issues: localisation, features, usability etc. (Dytczak, \& Ginda, \& Szpringier, 2009). There are both tangible and intangible features. Influence of tangible issues is easy to include when valuating objects. On the other hand, intangibles aren't easy to include as their tend to be to differently evaluated by distinct valuators. The evaluation of intangible influence is therefore very susceptible to valuator's subjective opinions. This creates risk of unaware or even purposeful distortion of influence of intangibles on final outcome of valuation. It is therefore important to de liver means for adequate valuation of intangibles influence on real estate object value. Application of such means serves not only the purpose of adequate including of intangibles but also de livers means for validation of valuation process and value estimation correctness in particular. The second purpose is especially useful for credibility check of a valuator.

\section{Proposed approach}

The approach applies AHP/ANP. Utilisation of this method is, however, suitable rather for small sets of objects. A considerable number of evaluated real estate objects requires therefore to apply a special extension to AHP/ANP application. A general two-stage approach can be applied with this regard. It makes use of a decomposition principle.

The first stage is based on discrimination of full population real estate objects. The objects are divided into clusters. Each cluster consists of similar components. Number of derived clusters and their cardinality should correspond to capability of AHP/ANP pair-wise comparisons. Number of clusters and number of cluster components $n$ ought to be therefore not smaller than five and not larger than nine (Saaty, \& Ozdemir, 2003). If number of clusters and/or their cardinality were still too large, further identification of clusters is necessary. A hierarchy of cluster levels is thus created. The process of creation of clusters ends when number AHP/ANP-tractable clusters inside each hierarchy level is obtained.

The limit of number of cluster components makes estimation of total upper limit of number of evaluated objects possible. Seven essential hierarchy levels are usually regarded as the upper tractable AHP/ANP hierarchy limit (Fig.1). Because at most 9 objects can comprise a single cluster, the largest tractable number of objects is therefore equal to $9^{7}$ i.e. 4782969. The limit seems acceptable even for a large real estate management agency. It is also possible evaluations due to a considered attribute will recur in the case of different real estate objects. Real number of objects which differ with regard to the attribute seem therefore to be smaller a lot. 


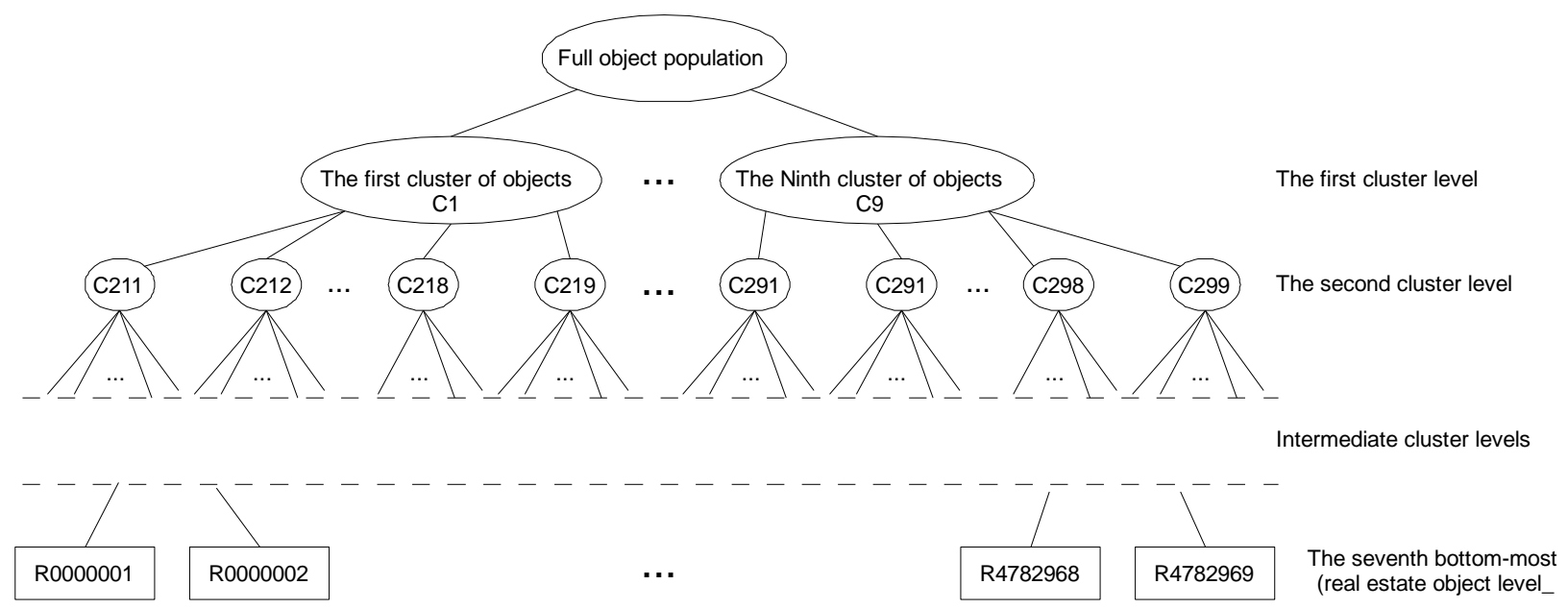

Fig.1. Scheme for clustering of real estate objects

Tangible attributes don't need special treatment due to numerical nature of evaluations. Priorities for real estate objects with regard to these features are thus easily estimated thanks to absolute evaluations. The presented approach treats tangibles and intangibles in different ways. It is therefore different from the approach presented in (Dytczak, \& Ginda, \& Szpringier, 2009) because AHP/ANP application is now limited to estimation of priorities for intangible features of valuated real estate objects only.

A need for seamless comparability of priorities, no matter what nature the object attributes are, requires application of the same local priority description for both tangible and intangible features. The idealised as well as normalised priorities can be applied with this regard. Application of both kinds of local priority description is suitable for application of common weighted aggregation procedures. Unitarised priorities can be also utilised. However, their usability is limited to an additive aggregation procedure. Estimation of importance weights for object attributes is also based on AHP/ANP hierarchy utilisation.

Application of devoted hierarchies is needed for estimation of objects due to distinct intangibles. Each hierarchy delivers means for identification of priorities and a single ranking of real estate objects due to a considered feature. Clustering of features is based on initial values of devoted attribute. The value is based on application of an ordinal measurement scale. Utilisaton of such scale is natural in the case of real estate valuation (Dytczak, \& Ginda, \& Szpringier, 2009). The evaluation results from description of object which is a part of official report delivered by a valuator in a valuation statement. Local priorities are obtained using an ordinal measurement scale provided by the valuator.

The procedure of partial priorities and rankings of objects with regard to an intangible object attribute looks as follows:

1. Objects are divided into suitable numbers of clusters and components. Any discriminant or cluster analysis tool can be applied to achieve that. Any ordinal scale can be applied to evaluate objects with regard to an attribute. A hierarchy of object clusters is the result of the stage.

2. Importance relations between clusters of objects and objects which belong to a specified hierarchy level are evaluated using pair wise comparisons. The relations are processesed on a level basis just like in the case of typical AHP/ANP analys is without feedback (classic AHP). Local priorities for objects due to a devoted attributes are defined. They result from a typical, level-by-level AHP/ANP synthesis just like in the case of AHP/ANP model without feedback.

Weights for attributes required for final aggregation of priorities result from AHP/ANP application as well. The case of numerous attributes can be addressed in a way similar to coping with numerous real estate objects. Standard, pivot object-based mechanisms can be also applied with this regard. 
Estimation of real estate object value is calculated using its dimensionless aggregated priority. The cluster analysis approach can be applied to obtain it. A multi-dimensional space of object attributes is utilised with this regard. Monetary value of considered real estate object can be then estimated using data for the most similar objects with regard to a complete set of features. For example, an average value of real transaction value of the closest objects can be utilised. The approach is open with regard to applied clustering methodology. It seems that application of any suitable cluster analysis and discriminant approaches out of numerous approaches (Kolenda, 2006) available is possible.

\section{Application of the approach}

The approach has been applied for valuation purpose of a local division of a governmental real estate management agency. The agency deals with thousands of real estate objects. Initial application of the approach delivers interesting results. They will be presented during the symposium. They encourage, however, to state that the approach seems a valuable tool for valuation and utilisation.

It is sure that only existence of a complete database with regard to features of managed real estate objects would make exploitation of full potential of the approach possible. Such database comprises required condition for successful introducing of the approach into practice in an agency. The process of full data basis preparation in a considered agency is therefore underway. The more thorough results will follow immediately after the database or its essential part is ready.

\section{Conclusions}

Proposed approach comprises basis for a decision support system devoted to massive valuation of real estate objects for real estate agencies which deal with numerous objects. It is currently in implementation phase. Introductory results of the implementation are very encouraging. However, it is sure that only application of data pertaining for a numerous set of objects will make trustful validation of the approach possible.

Another problem with application of the approach in practice pertains to massive data acquisition for pair-wise comparisons with regard to local object prioritization due to intangible attributes. It seems that search for application of auxiliary tools which would help with it is necessary. For example, utilisation of trained artificial neural networks seems a potentially good choice. They could make replacement of real experts possible. Application of some alternative AHP/ANP tools like scales and prioritisation methods can also be helpful with this regard e.g. including means necessary to take into account different expert profiles and ranges of object feature evaluations. The approach seems to be open enough for taking advantage of any suitable extension.

\section{REFERENCES}

Dytczak M., \& Ginda G., \& Szpringier M. (2009). Wieloatrybutowa wycena wartości nieruchomości z uwzględnieniem czynników trudno mierzalnych [Multi-attribute valuation of real estate objects including intangibles]. Zeszyty Naukowe WSB we Wroclawiu, no. 11(11), pp.275-293.

Kolenda M. (2006). Numerical Taxonomy. Classification, Ranking and Analysis of Multivariable Objects. Akademia Ekonomiczna we Wrocławiu. Wrocław.

Saaty T.L., \& Ozdemir M.S. (2003). Why the magic number seven plus or minus two. Mathematical and Computer Modelling, 38(3-4):233-244. 